\title{
POWER QUALITY IMPROVEMENT OF A 2.8kVA SINGLE PHASE GENERATOR USING A DOUBLE-TUNE FILTER
}

\author{
J. O. Eyenubo* \\ Dept of Electrical/Electronic Engineering, Delta State Univ., Oleh Campus, Delta State, Nigeria \\ E-mail address: eyenubo63@yahoo.com
}

\begin{abstract}
Improving power quality plays a vital role in power distribution systems. Nonlinear loads generate harmonics that disturbs power supply. This paper presents a control strategy in which data collected from a single phase generator (2.8 kVA) using 'Owon' oscilloscope. A double-tune filter configuration was developed to analyze the harmonic contents associated with the non-linear loads on the single phase generator. MATLAB Simulation was carried on the data collected (voltage and frequency) from the power source using the double-tuned filter. It can be established from the frequency measured instead of the usual $50 \mathrm{~Hz}$ on nameplate, the measured value was $46.160 \mathrm{~Hz}$ and the voltage values on Tables 1 and 2 that were transformed into waveforms and spectrum.
\end{abstract}

Keywords: Harmonics, Total harmonic distortion, (VTHD), Matlab/Simulink, Filter.

\section{INTRODUCTION}

Power quality issues arising in day to day life creates much inconveniences to customers and utilities. After the power electronic revolution, many consumers are connected to power electronic controlled loads as it gives so much flexibility, smooth control and many advantages. Harmonics causes imbalance in the power system, malfunctioning of circuit breaker, damaging sensitive equipment and even generating heat in the neutral conductor. It is essential to eliminate harmonics in the power system to improve the power quality. Power quality improvement entails having voltage and current waveforms in pure sinusoids. Many current harmonic filters are mentioned in literatures, but recent trends for double tuned and triple tuned filters to eliminate current harmonics when connected to nonlinear loads has become a more recent approach of eliminating harmonics causing low power quality in power distribution systems.

Research on double-tuned filter attract people's attention: this may have resulted in losses, controllability and parameter calculations. Literature, put forward an algorithm about parameters calculation of double-tuned filter, but the operation process is complicated [1-6]. Thus, a new method on double- tuned filter parameters calculation has been explored; it needs to solve equations that contains a large amount of computation.

\section{METHODOLOGY DOUBLE-TUNE FILTER:}

was developed for this work, the analysis of the filter was done taking a section of the filter to analyze the parameters, Matlab software was used for the simulation to obtain result [7].

2.1 Calculation of bank parameters: resonant frequency and impedance

The filter reactor size can now be selected to tune the capacitor to the desired frequency as follows [8-11]:

$$
L=\frac{1}{(2 \pi f)^{2}(r h)^{2} C}
$$

where $h$ is the harmonic order to which the filter is tuned, $r$ is an empirical factor smaller than one, the typical value of $r$ is 0.94 and $f$ is the frequency at resonance, $\mathrm{C}$ is capacitance

Reactors reduce harmonic currents; the definition of the percentage impedance of a reactor is:

$$
\% I_{\text {imp }}=\frac{I_{\text {fund }} \times 2 \times \pi \times f \times L \times 100}{V_{L}}
$$

*Author, tel: $+234-816-739-3531$ 
where, $I_{\text {fun }}=$ fundamental current, $I_{\text {imp }}=$ impedance current . Hence the inductance of a reactor can be calculated from:

$$
L=\frac{\% I_{\text {imp }} \times V_{L}}{I_{\text {fund }} \times 2 \times \pi \times f \times \sqrt{3} \times 100}
$$

By equating the inductive reactance and capacitive reactance, we have:

$$
L=\frac{1}{\omega_{n}^{2} C}
$$

where: $\omega_{n}=$ normal resonance frequency and $V_{L}=$ line voltage

The quality factor of the coil is given by:

$$
\begin{aligned}
& Q=\frac{\omega_{n}-L}{R} \\
& R=\frac{\omega_{n}-L}{Q}
\end{aligned}
$$

where, $\mathrm{Q}=$ power in $\mathrm{kVA}, \mathrm{L}=$ inductance in $\mathrm{mH}, \mathrm{C}=$ capacitance in $\mu F$ and $\mathrm{R}=$ resistance in ohm

\section{RESULTS AND DISCUSSION}

Table 1 shows the results in the output waveform shown in Figure 3 showing the voltage waveform and harmonic spectrum before simulation laden with nonlinear loads. The value of total harmonic distortion before simulation was carried out was found to be $\mathrm{V}_{\mathrm{THD}}$ $=0.09536=9.536 \%$. Table 2 showed the filtered result after simulation using the double-tuned filter that the total harmonic distortion is $\mathrm{V}_{\mathrm{THD}}=0.04122=$ $4.122 \%$ which shows a reduction in the value of the $\mathrm{V}_{\mathrm{THD}}$, this complies with the required IEEE standard of $5 \%$.

Figure 4 shows the voltage waveform and harmonic spectrum under non-linear load condition. Figure 5 shows the voltage waveform and harmonic spectrum after filtering/simulation.
In conclusion, an improvement of total harmonic distortion can be achieved if these harmonics are totally attenuated. The choice of filter elements resistor, inductor and capacitor will enhance a more accurate result. As a criterion of IEEE standard; excessive harmonic current/voltage injection distortion is incumbent on utility and consumer that should be resolved within a mutually acceptable framework of IEEE 519 - 1992. This recommends the limits on harmonic distortion according to two distinct criteria:

a) A limitation is placed on the level of harmonic voltage that utility can supply to consumer.

b) There also is a limitation on the amount of harmonic current that a consumer can inject into utility network.

Mitigation of power quality problem may take place at different level of power system: at power plant, at transmission lines and stations, at primary and secondary distribution networks as well as at the service equipment and customers' building wiring. It should be noted that the problem of power quality cannot be eliminated completely except some equipment can be done away or if lightning strike can be prevented or if fault can be eliminated. However, effect of power quality problem can be drastically reduced to almost zero.

For future investigation of actual operational frequency as against the fictitious frequency on name plates of single phase generators should be verified. Simulation strategies and control algorithms should be improved; besides, the selection of harmonic elimination methods other than the filter method can bring additional performance that may result in higher voltages and power.

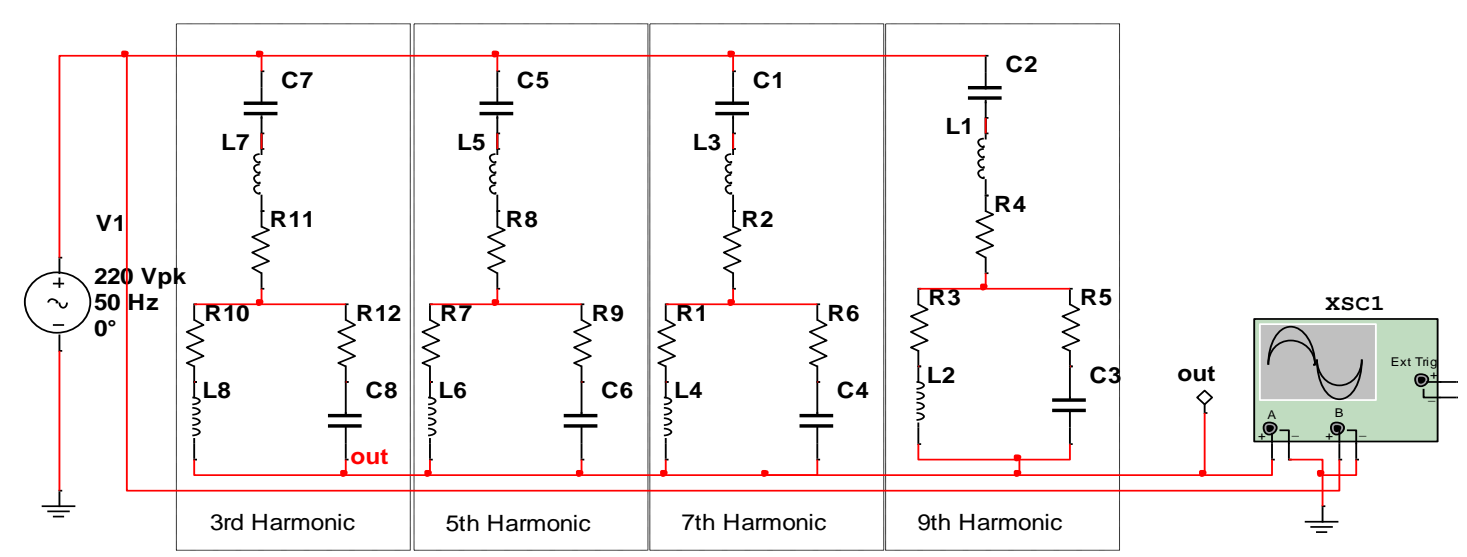

Figure 1: Double-tune Filter circuit for simulation [7]. 
The values obtained from Figure 1 include the following:

$\mathrm{C}_{1}-\mathrm{C}_{3}=728.2784 \mu \mathrm{F} ; \mathrm{C}_{4}-\mathrm{C}_{6}=436.967 \mu \mathrm{F} ; \mathrm{C}_{7}-\mathrm{C}_{8}=312.1193 \mu \mathrm{F}$

$\mathrm{L}_{1}-\mathrm{L}_{3}=0.0104 \mathrm{mH} ; \mathrm{L}_{4}-\mathrm{L}_{6}=0.01733 \mathrm{mH} ; \mathrm{L}_{7}-\mathrm{L}_{8}=0.02427 \mathrm{mH}$

$\mathrm{R}_{1}-\mathrm{R}_{3}=1.5453 \mathrm{k} \Omega ; \mathrm{R}_{4}-\mathrm{R}_{6}=0.92718 \mathrm{k} \Omega ; \mathrm{R}_{7}-\mathrm{R}_{9}=0.6623 \mathrm{k} \Omega ; \mathrm{R}_{10}-\mathrm{R}_{11}=0.5151 \mathrm{k} \Omega$

Table 1: Power source generator, $2.8 \mathrm{kVA}$, at frequency, $46.160 \mathrm{~Hz}$ before filtering

\begin{tabular}{ccccccc}
\hline harm & time & \multicolumn{2}{c}{ Voltage } & Voltage Magnitude $(V)$ & Phase angle after filtering & \multirow{2}{*}{ scope_data } \\
\cline { 3 - 6 } no & $(\mathrm{sec})$ & $\mathrm{a}_{\text {na }}$ & $\mathrm{bna}_{\text {na }}$ & $\mathrm{C}_{\text {na, }} \%$ & $(\mathrm{rad})$ & \\
\hline 1 & 0 & 3651638.73 & 321872.47 & 3665796.96 & 0.110149879 & -4800000 \\
2 & 0.01 & 0.00 & 0.00 & 0.00 & 0 & -4600000 \\
3 & 0.02 & 270281.23 & 61753.92 & 277246.26 & 0.312852443 & -4600000 \\
4 & 0.03 & 0.00 & 0.00 & 0.00 & 0 & -4600000 \\
5 & 0.04 & 138900.06 & 39450.32 & 144393.75 & 0.583467323 & -4400000 \\
6 & 0.05 & 0.00 & 0.00 & 0.00 & 0 & -4400000 \\
7 & 0.06 & 89451.04 & 27195.04 & 93493.63 & 0.567563596 & -4400000 \\
8 & 0.07 & 0.00 & 0.00 & 0.00 & 0 & -4400000 \\
9 & 0.08 & 83063.43 & 21883.64 & 85897.77 & 0.408629782 & -4400000 \\
10 & 0.09 & 0.00 & 0.00 & 0.00 & 0 & -4400000 \\
11 & 0.1 & 59386.14 & 17292.86 & 61852.70 & 0.490473509 & -4400000 \\
12 & 0.11 & 0.00 & 0.00 & 0.00 & 0 & -4200000 \\
13 & 0.12 & 44926.29 & 13585.88 & 46935.57 & 0.401379124 & -4200000 \\
14 & 0.13 & 0.00 & 0.00 & 0.00 & 0 & -4200000 \\
\hline
\end{tabular}

Table 2: Power source generator, $2.8 \mathrm{kVA}$, at frequency, $46.160 \mathrm{~Hz}$ after filtering

\begin{tabular}{ccccccc}
\hline harm & time & \multicolumn{2}{c}{ Voltage (volts) } & Voltage Magnitude $(V)$ & Phase angle after filtering & \multirow{2}{*}{ Scope data } \\
\cline { 3 - 6 } no & $(\mathrm{s})$ & ana & $b_{\text {na }}$ & $C_{\text {na, } \%}$ & $(\mathrm{rad})$ & \\
\hline 1 & 0 & 3605142.36 & 398719.86 & 3627124.06 & 0.627917441 & -4800000 \\
2 & 0.01 & 0.00 & 0.00 & 0.00 & 0 & -4600000 \\
3 & 0.02 & 145374.86 & 47025.21 & 152791.43 & 0.82462448 & -4600000 \\
4 & 0.03 & 0.00 & 0.00 & 0.00 & 0 & -4600000 \\
5 & 0.04 & 60515.75 & 39948.59 & 72512.38 & 1.17673201 & -4400000 \\
6 & 0.05 & 0.00 & 0.00 & 0.00 & 0 & -4400000 \\
7 & 0.06 & 51048.44 & 32545.25 & 60540.37 & 1.1951422 & -4400000 \\
8 & 0.07 & 0.00 & 0.00 & 0.00 & 0 & -4400000 \\
9 & 0.08 & 45766.03 & 19816.83 & 49872.20 & 0.35760337 & -44000000 \\
10 & 0.09 & 0.00 & 0.00 & 0.00 & 0 & -44000000 \\
11 & 0.1 & 34677.54 & 18517.69 & 39312.04 & 0.32335801 & -44000000 \\
12 & 0.11 & 0.00 & 0.00 & 0.00 & 0 & -4200000 \\
13 & 0.12 & 34485.82 & 14636.46 & 37463.29 & 0.31366066 & -4200000 \\
14 & 0.13 & 0.00 & 0.00 & 0.00 & 0 & -4200000 \\
\hline
\end{tabular}



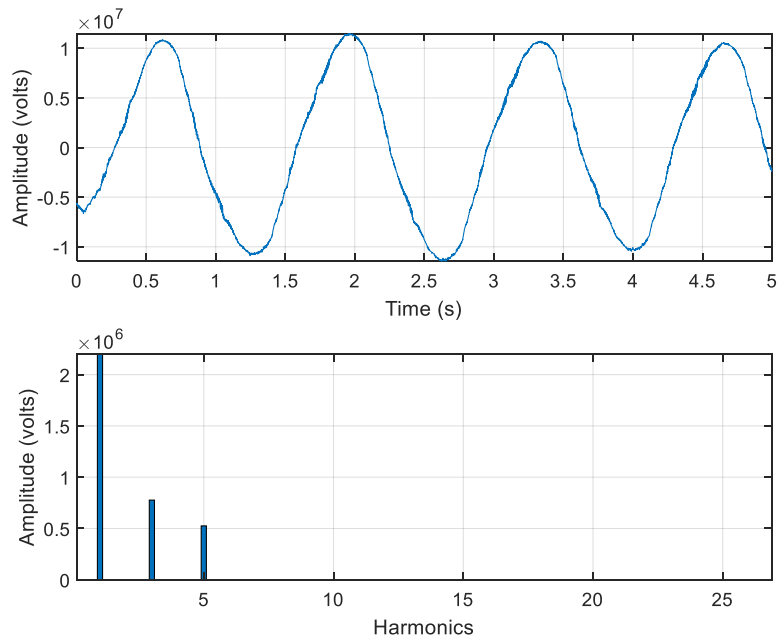

Figure 2: showing the voltage waveform and harmonic spectrum before simulation. The figure shows a sine wave with amplitude of 1 volt and the 10MVolts/Div is set to 0.5 volts/division while Timebase is set to 0.005 seconds (or 200 macro-seconds/division) on the vertical axis.
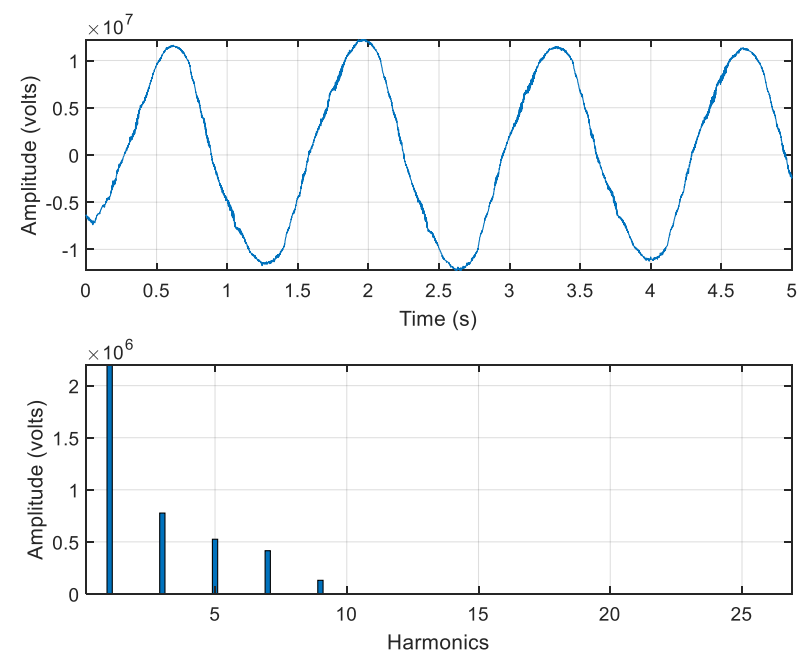

Figure 3: showing the voltage waveform and harmonic spectrum under non-linear load condition. The figure shows a sine wave with amplitude of 1 volt and the 10MVolts/Div is set to 0.5 volts/division while Timebase is set to 0.005 seconds (or 200 macroseconds/division) on the vertical axis.
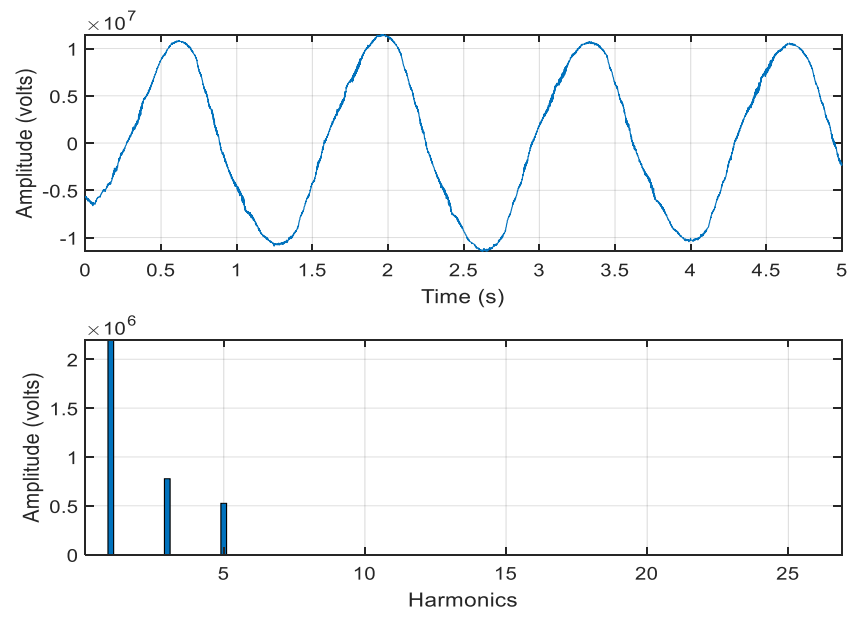

Figure 4: Voltage waveform and harmonic spectrum after filtering. The figure shows a sine wave with amplitude of 1 volt and the 10MVolts/Div is set to 0.5 volts/division while Timebase is set to 0.005 seconds (or 200 macro-seconds/division) on the vertical axis.

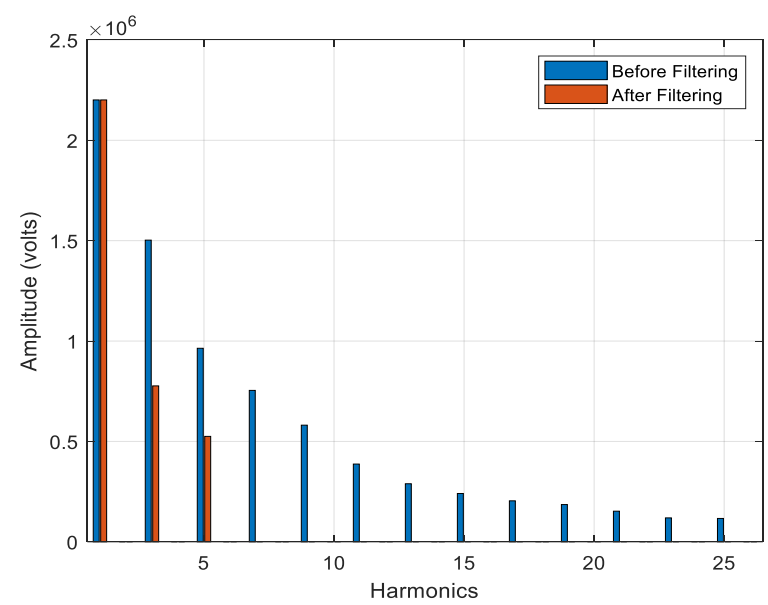

Figure 5: Harmonic spectrum before and filtering. Timebase is set to 0.005 seconds (or 200 macroseconds/division) on the vertical axis

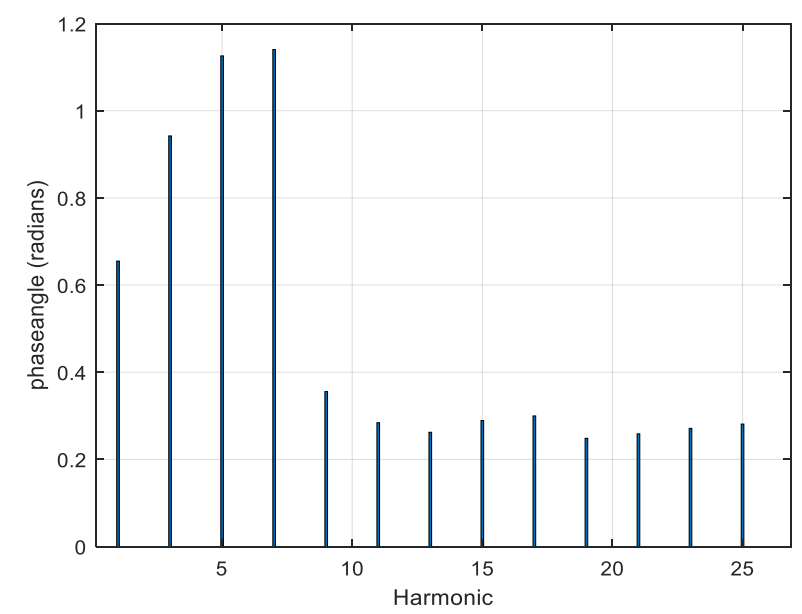

Figure 6: Phase angle after filtering, as obtained from Table 2 after filtering 


\section{REFERENCES}

[1]. XIAO Yao and SHANG Chun, Multi-tuned Passive Filters with Less Power Loss Automation Electric Power Systems, 19(30): 69-72.

[2]. Kang Ming-cai, and Zhou Jia-hua, Compensates the double tuned filter element parameter change based on controllable reactor[C]// Electricity Distribution, pp. 406-415, CICE, 2008.

[3]. Yu Ming tao, Chen Jianye, and Wang Weian, A double tuned filter based on controllable reactor [C] Power Electronics, Electrical Drives, Automation and Motion, SPEEDAM, 2006: 12321235.

[4]. Xiao Yao, , Algorithm for the Parameters of Double Tuned Filter, Proceedings of the 8th International Conference on Harmonics and Quality of Power, 14-16 Oct. 1998, pp. 154-157.

[5]. LI Pu-ming, and XU Zheng, (2008), Algorithm for the Parameters of AC Filters in HVDC Transmission System [J]. Proc. CESS, 16(28):115-120.

[6]. Kang Ming-cai, Zhiqian Bo, and Xiping Zhao, (2010), The Parameters Calculation and Simulation Research about Two Types Structure of Double-tuned Filter[C]// Universities Power
Engineering Conference(UPEC), 45th International. 2010: 1-4.

[7]. Eyenubo O. J. and Ubeku E. U, "Power Quality Analysis: The Reduction of Harmonic Contents in Power Systems USING Electronic Filter" Ph. D Thesis, University of Benin Department of Electrical and Electronic Engineering, 2015.

[8]. Liao H. W and Akagi H., 2007 "Instantaneous Reactive Power Compensators Comprising Switching Devices without Energy Storage Components", IEEE Trans. Ind. Appl. 20 (3) 625630

[9]. Huang C.L., Michael E, and Habetler T.G 2001 'The Mathematics of Circuit Analysis', John Wiley and Sons, pp. 267-279, INC., New York,

[10]. Meinardus G., 2012, "Approximation of Functions: Theory and Numerical Methods". New York: Springer-Verlag, IEEE Trans. Instrum. Meas., vol. IM-37, pp. 656-657

[11]. Susan, D. and S. Jayalalitha, 2011. "Chebyshev filters using simulated inductor", http://www.sastra.edu/staffprofiles/schools/seee. php?staff id=C233

http://www.sastra.edu/staffprofiles/schools/seee.php ?staff id=C545 